\title{
Recurrent Perianal Abscess in a Patient With Hermansky- Pudlak Syndrome Associated Granulomatous Colitis: A Case Report
}

\author{
Ahmet Omak, Tevfik Kıvılcım Uprak, Wafi Attaallah \\ Department of General Surgery, Marmara University School of Medicine, Istanbul, Turkey
}

Hermansky-Pudlak syndrome (HPS) is a rare genetic disease consisting of the triad of oculocutaneous albinism, bleeding diathesis, and pigmented reticuloendothelial cells. In HPS patients' granulomatous colitis could be an additional feature and perianal abscess could be seen in such patients. We report a patient with HPS-associated granulomatous colitis, refractory to medical treatment, and perianal involvement. Patients with HPS-associated granulomatous colitis and perianal involvement may require multiple surgical interventions and there is no consensus yet for treatment in such patients.

Keywords: Hermansky-Pudlak syndrome, Colitis, Proctitis, General surgery

\section{INTRODUCTION}

Hermansky-Pudlak syndrome (HPS) is a rare genetic disorder described in 1959 by Hermansky and Pudlak [1]. HPS is characterized by oculocutaneous albinism, bleeding diathesis caused by abnormal platelet function, and pigmented reticuloendothelial cells. Systemic involvements such as pulmonary fibrosis and granulomatous colitis are described in HPS patients [2]. Renal failure, cardiomyopathy, and granulomatous hepatitis could be additional features [3].

Granulomatous colitis associated with HPS has similarities with Crohn disease such as non-necrotizing granulomas on colonoscopic biopsies and perianal disease with perianal abscess. However, characteristic features of Crohn disease-like ileal involvement, intestinal fistulation, or typical perianal lesions are usually not seen in HPS patients [4]. Additionally, perianal-perirectal abscess in HPS patients is previously described in literature $[5,6]$. In

Received: Jun 4, 2021 - Revised: Sep 20, 2021 - Accepted: Sep 23, 2021 Correspondence to: Ahmet Omak, M.D.

Department of General Surgery, Marmara University School of Medicine,

Fındıklı, Başı̈üyük Yolu No: 9-2, Maltepe, Istanbul 34854, Turkey

Tel: +90-534-410-4024,E-mail: dr.ahmetomak@gmail.com

ORCID: https://orcid.org/0000-0002-7108-9351

(C) 2021 The Korean Society of Coloproctology

This is an open-access article distributed under the terms of the Creative Commons Attribution NonCommercial License (https://creativecommons.org/licenses/by-nc/4.0) which permits unrestricted non-

commercial use, distribution, and reproduction in any medium, provided the original work is properly cited. this report, we present a case of a patient with HPS that was concomitant with granulomatous colitis and complicated perianal fistula.

\section{CASE REPORT}

A 37-year-old albino and autistic male was presented to an internal medicine clinic in 2008 complaining of constipation and intermittent diarrhea. Colonoscopy suggested inflammatory bowel disease. Histopathological examination showed granulomatous colitis. In differential diagnosis, tuberculosis was ruled out and the patient was prediagnosed with Crohn disease. The patient started on sulfasalazine and this treatment led to relief in symptoms. Due to fistulizing perianal disease, infliximab was added to medical treatment in 2010. After genetic consultation in 2012, the patient was diagnosed with HPS. During follow-up, laboratory tests showed positive hepatitis surface antigen and antiviral treatment began. Between 2012 and 2016, the patient was repeatedly admitted because of recurrent perirectal abscess. Drainage and seton application were applied to the patient. Magnetic resonance imaging (MRI) showed the right intersphincteric fistula and abscess in right ischiorectal fossa (Fig. 1).

In 2018, the patient was referred to the clinic because of hematochezia and diarrhea. Colonoscopy revealed aphthous ulcers in the sigmoid colon and seton observed in anus. Mesalamine treatment was initiated. Histopathological examination confirmed granulomatous colitis. Perianal MRI shows a regression in abscess 


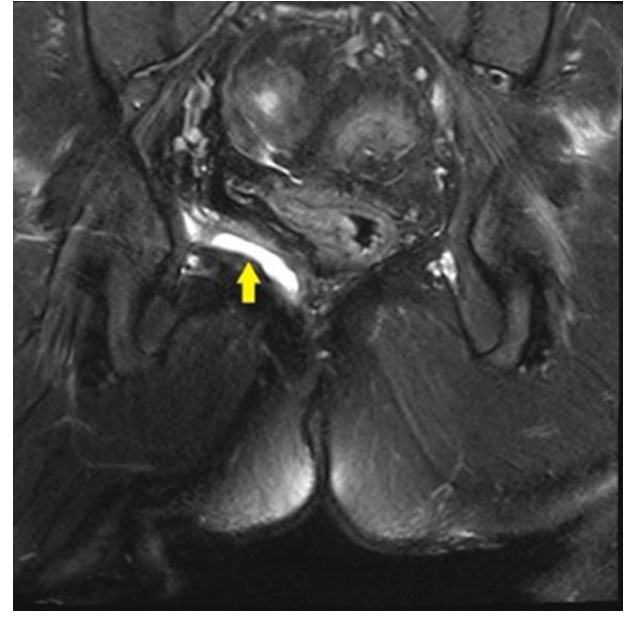

Fig. 1. T2-weighted magnetic resonance imaging. Right intersphincteric fistula and abscess in the right ischiorectal fossa (arrow).

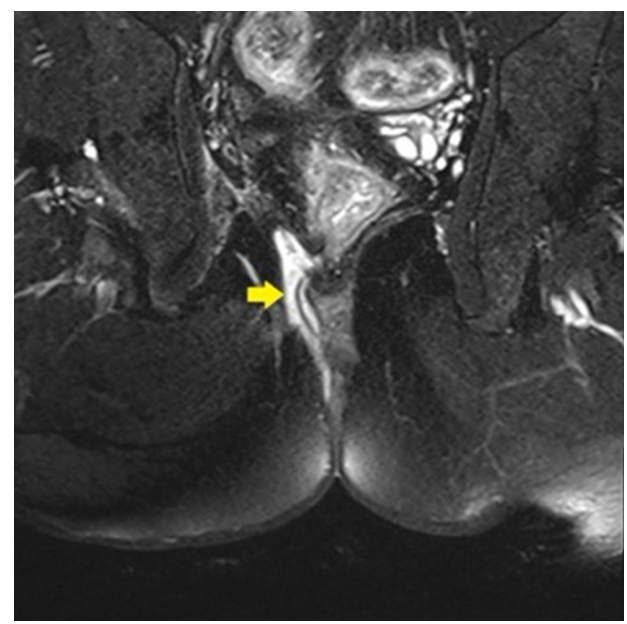

Fig. 2. T2-weighted magnetic resonance imaging. Suprasphincteric component of collection (arrow).

size compared to 2016 MRI, but new imaging revealed a suprasphincteric component of collection (Fig. 2). Fistulotomy and mucosal advancement flap repair was performed. He was discharged on the 6th postoperative day. On the eleventh postoperative day, the patient complained of bloody stool and was hospitalized. Anemia was detected and 3 units of red blood cell suspension were transfused. After regression of the symptoms, the patient was discharged after 6 days. He took sulfasalazine for 6 months and after that infliximab treatment was given monthly. Due to diarrhea, perianal discharge, and renal failure, the patient was hospitalized in August 2019. He was under treatment of mesalamine, certolizumab, tenofovir, quetiapine, and olanzapine. Perianal MRI showed fistula and nonoperative treatment was suggested. After 2 months, all medications stopped because of re-

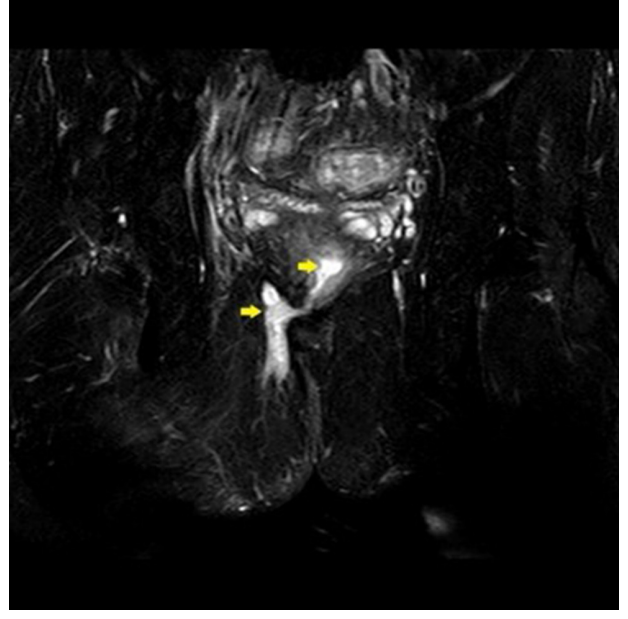

Fig. 3. T2-weighted magnetic resonance imaging. Progression with multiple abscesses (arrows).

nal failure and hemodialysis was done.

In the follow-up period, hematochezia occurred, and the patient was hospitalized. Computed tomography (CT) showed perianal fistula and abscess and perianal MRI was coherent with CT. Rectal examination described internal drainage of the abscess and no surgical interventions were recommended. Certolizumab, entecavir, and antibiotics were started. One month later, perianal MRI showed regression on abscess size. A few months later under the certolizumab therapy, the patient was hospitalized because of fever. There was no obvious finding in radiological images. Because of fever, examination under general anesthesia was done but there was no drainable abscess. One month later, perianal MRI showed progression with multiple abscesses (Fig. 3). Perianal abscess drainage, diversion sigmoid ostomy, and seton placement were performed. On the 14th postoperative day, the patient was presented to the emergency department with the complaint of bleeding from the edge of the colostomy, and the bleeding stopped spontaneously within 24 hours. The patient was still on follow-up for 1 year without any complications. Written informed consent was obtained for the publication of this case report and accompanying images.

\section{DISCUSSION}

HPS-associated granulomatous colitis is clinically similar to ulcerative colitis and pathologically Crohn disease [4-6]. Superficial and deep ulcers and in some cases pseudo polyps can be seen in colonoscopy [4]. Large ulcers extending to the muscularis mucosa, granular pigmentation, and non-necrotizing granulomas can be seen in histopathological examination $[2,6]$. The pathogenesis of HPS-associated granulomatous colitis has not been elucidated yet. It is suggested that in patients with HPS accompanied by granulomatous colitis and pulmonary fibrosis, the ceroid pig- 
ment accumulated in the tissues causes a nonspecific reaction, resulting in damage and fibrosis [7-9].

Sherman et al. [5] reported perianal and perirectal disease with similar findings to Crohn disease in patients with HPS-associated granulomatous colitis. Three of 4 patients had perirectal involvement, and it was suggested that conservative treatment and in some cases incision and drainage may be required [5].

Due to its similarity with Crohn disease, medical therapies applied in Crohn disease have been tried in patients with HPS-associated granulomatous colitis and different success rates have been reported in different series. In a case series, it was reported that 2 of 4 HPS-associated granulomatous colitis patients with perianal involvement responded well to anti-tumor necrosis factor agents, one was partial and the other showed a poor response [10]. Our patients also have been given multiple medications including sulfasalazine, infliximab, azathioprine, mesalamine, and certolizumab with the collaboration of the gastroenterology and internal medicine department. However, patient did not benefit from the medical treatments in terms of perianal disease.

In this case, multiple surgical procedures were performed on the patient with perianal abscess, unresponsive to medical treatment. Since the patient was unresponsive to medical and conservative treatment, diversion sigmoid ostomy was performed. There is no consensus on the management of patients with perianal involvement in the literature, and conservative treatment similar to Crohn disease is recommended [11].

In conclusion, the pathophysiology of HPS-associated granulomatous colitis should be defined for the treatment and follow-up of patients with HPS-associated granulomatous colitis with perianal involvement, and more studies are needed. It should be kept in mind that bleeding may occur after surgical treatment in such patients, and the importance of multidisciplinary approach should not be neglected.

\section{CONFLICT OF INTEREST}

No potential conflict of interest relevant to this article was reported.

\section{REFERENCES}

1. Hermansky F, Pudlak P. Albinism associated with hemorrhagic diathesis and unusual pigmented reticular cells in the bone marrow: report of two cases with histochemical studies. Blood 1959; 14:162-9.

2. Schinella RA, Greco MA, Cobert BL, Denmark LW, Cox RP. Hermansky-Pudlak syndrome with granulomatous colitis. Ann Intern Med 1980;92:20-3.

3. Witkop CJ Jr. Albinism. Clin Dermatol 1989;7:80-91.

4. Grucela AL, Patel P, Goldstein E, Palmon R, Sachar DB, Steinhagen RM. Granulomatous enterocolitis associated with Hermansky-Pudlak syndrome. Am J Gastroenterol 2006;101:2090-5.

5. Sherman A, Genuth L, Hazzi CG, Balthazar EJ, Schinella RA. Perirectal abscess in the Hermansky-Pudlak syndrome. Am J Gastroenterol 1989;84:552-6.

6. Hazzan D, Seward S, Stock H, Zisman S, Gabriel K, Harpaz N, et al. Crohn's-like colitis, enterocolitis and perianal disease in Hermansky-Pudlak syndrome. Colorectal Dis 2006;8:539-43.

7. Witkop CJ, Townsend D, Bitterman PB, Harmon K. The role of ceroid in lung and gastrointestinal disease in Hermansky-Pudlak syndrome. Adv Exp Med Biol 1989;266:283-97.

8. Hussain N, Quezado M, Huizing M, Geho D, White JG, Gahl W, et al. Intestinal disease in Hermansky-Pudlak syndrome: occurrence of colitis and relation to genotype. Clin Gastroenterol Hepatol 2006;4:73-80.

9. Huizing M, Pederson B, Hess RA, Griffin A, Helip-Wooley A, Westbroek W, et al. Clinical and cellular characterisation of Hermansky-Pudlak syndrome type 6. J Med Genet 2009;46:803-10.

10. Demirtas CO, Alahdab YO, Kani HT, Atug O, Imeryuz N. Treatment of Hermansky-Pudlak syndrome Associated granulomatous colitis with anti-TNF agents: case series and review of literature. Eur J Gastroenterol Hepatol 2019;31:1597-600.

11. Girot P, Le Berre C, De Maissin A, Freyssinet M, Trang-Poisson C, Bourreille A. Crohn's-like acute severe colitis associated with Hermansky-Pudlak syndrome: a case report. World J Gastroenterol 2019;25:1031-6. 